\title{
Nudging: A lesson in the theatrics of choice
}

Magda Osman ${ }^{\mathrm{a}}$, Yiling Lin ${ }^{\mathrm{a}}$, Richard Ashcroft ${ }^{\mathrm{b}}$

${ }^{a}$ Psychology Dept. School of Biological and Chemical Science, Queen Mary University of London, London, E1 4NS, UK;

${ }^{b}$ School of Law, Queen Mary University of London, London, E1 4NS, UK;

Correspondence concerning this article should be addressed to Magda Osman, School of Biological and Chemical Science, Queen Mary University of London, Mile End Rd, London, E1 4NS. E-mail: m.osman@qmul.ac.uk. 
NUDGING: A LESSON IN THE THEATRIC OF CHOICE

\begin{abstract}
The aim of this piece is to clarify three key matters: (a) the extent to which, as citizens, our volition is impacted as a result of the implementation of nudges in the health domain; (b) the efficacy of educational campaigns as a means of behavioral change relative to other nudges as well as typical regulatory instruments; and (c) the empirical, theoretical, and practical details that ethical debates concerning nudges might want to consider.
\end{abstract}


NUDGING: A LESSON IN THE THEATRIC OF CHOICE

\section{Acknowledgments}

The completion of this research was funded by Queen Mary University of London Life Sciences Initiative Studentship (LSIPGRS). In addition, we would like to thank William Nelson for his helpful discussions and advice on an earlier draft of this manuscript, and in particular for his inspired suggestion for the title. 


\section{NUDGING: A LESSON IN THE THEATRIC OF CHOICE}

A few points of clarification are needed so that our position on important matters is explicitly made before we embark on a direct response to the provocative and interesting comments by Marjanovic (2017/this issue). and by Rauh (2017/this issue). The first matter concerns the starting point of our review (Lin, Osman, \& Ashcroft, 2017/this issue). The nudges are applied in most aspects that concern health, wealth, and well-being. Their wide acceptance as a method of behavioral change motivated the reason behind us carefully evaluating the theoretical foundations that explains how nudges work, not in principle as suggested by Marjanovic but in practice. The pervasiveness of nudges is also the reason behind us examining the empirical support for nudges. Many practitioners and policymakers are persuaded to use nudges, and so this audience should be given a means of making an informed choice based on the efficacy of nudges in the health domain.

The second matter of clarification concerns the theoretical evaluation of the dual-system framework that underpins nudges. After discussing the insurmountable issues with the dualsystem framework, we present a way of conceptualizing the theory behind nudges from a single-system framework. Proposing a single system account of choice behavior is not simply updating a dual-system account (Majanovic, 2017/this issue). It stands in contrast to, and is an alternative to, a dual-system account. If there were any ambiguity that we do not side with a dual-system framework, the reader might like to consult work critiquing the dual-system framework (De Neys, Cromheeke, \& Osman, 2011; Osman, 2004, 2007, 2010, 2013, 2014, 2016; Osman \& Stavy, 2006). Suffice it to say, based on considerable work dedicated to empirically and theoretically evaluating the dual-system framework, we do not find any sound theoretical or good empirical support for this framework, and it is certainly not a good basis for explaining the way nudges might work. 


\section{NUDGING: A LESSON IN THE THEATRIC OF CHOICE}

The third point of clarification is that we do not suggest that most of the bad decisions that people make are the result of biased automatic thinking (Majanovic, 2017/this issue) and that, by contrast, all good decisions are based on analytic slow thinking. Given our point of clarification with respect to our theoretical position, it should be clear that rendering bad decisions, the result of biased thinking is a far too simplistic explanation. We redirect the reader to the section of our review titled "Critical Issues With Dual-System Theories." Also, a point related to biased thinking and poor choices, we report evidence from a meta-analysis that concludes the knowledge of opaque nudges does impact the way they work (Holden, Zlatevska, \& Dubelaar, 2016). However, we do not propose, as Raul proposes, that opaque nudges (i.e., behavioral methods designed to target unconscious processes) cease to work when people are armed with enough knowledge about them — a point also often made by philosophers (Bovens, 2009; Grune-Yanoff, 2012). There is no evidence to show that by telling people how an unconscious nudge might work (e.g., smaller plates will mean you eat less food), like a magic trick, people see through the disguise, and so it is no longer effective. Actually, in the context of food and smaller plate sizes, and smaller packaging, awareness of the aim of the intervention, and/or awareness of food intake being monitored experimentally, contradicts this. Knowing how an opaque nudge works is at worst benign (Wansink, 2007) but more often likely to increase behavioral change in the "nudged" direction (Robinson, Kersbergen, Brunstrom, \& Field, 2014; Robinson, Proctor, Oldham, \& Masic, 2016).

At the heart of concerns around bad decision making, and the means of correcting it, is a deeply rooted worry - that opaque nudges are an imposition on our liberty, because they are designed to change our behavior without our awareness. We can comfortably say here, and reiterate what we presented in the review, that there is no reliable evidence to show that opaque nudges operate unconsciously in the first place. The most likely, but unfortunately the most prosaic, reason for opaque nudges not working is that they are incapable of achieving what they are 


\section{NUDGING: A LESSON IN THE THEATRIC OF CHOICE}

purported to do, which is correct an unconscious bias by tapping into unconscious processes, aside from the fact that bad decisions are not typically the result of biased unconscious processes. It is useful here to draw a parallel with a similar concern that arose in the context of advertising. The public and the academic community shared a deep worry about mind control via subliminal advertising (commercial and state) in the 1950s (and since), which in fact turned out to be a hoax (for discussion, see Osman, 2014). Even though there is no good evidence for controlling minds by tapping into the unconscious, the greater worry seems to be that the idea is still being perpetuated, and so many of us are willing to believe it.

In the remaining discussion we address three main points our commentators have made.

\section{Contribution for the loss of volition}

Majanovic (2017/this issue) comments that there are factors beyond our control, such as genetics and the course of aging, that make us susceptible to cardiovascular disease. However, he also notes that there are lifestyle choices we can make that are, to a large degree, under our control and that reduce our risk of cardiovascular disease (e.g., whether or not we smoke — and if we do, how much; whether or not we drink alcohol—and if we do, how much; whether or not we eat a balanced diet/exercise, etc.). Given that so many people struggle in regulating their lifestyle choices consistently toward good health behaviors, nudges step in to steer people toward the direction of positive outcomes and away from negative ones. This is with the assumption that people generally want to experience long-term positive outcomes; one might want to consult the many philosophical debates on the matter of whether this is ethically viable (Bovens, 2009; Grune-Yanoff, 2012; Schmidt, 2017). As Majanovic sets out, promoting and supporting positive health outcome is what nudges set out to do, and on this point Majanovic concludes that our loss of volition is the price we pay for this endeavor, which is a major problem given that a sign of our times is our preoccupation with taking back personal, political, 


\section{NUDGING: A LESSON IN THE THEATRIC OF CHOICE}

economic, and social control (McLeish, 2017). But we really don't need to have any contrition for the loss of volition with respect to nudges based on empirical evidence. So far, there just isn't any evidence that our volition is practically under threat from nudges, but the review does show that there is a considerable gulf between the goals that practitioners and policymakers have in mind and what nudges can actually deliver. Nevertheless, as severe are our conclusion is, and as strong a critique as it is for nudges, Majanovic and Raul seem to be left wanting more around the subject of volition, and so we take the opportunity to discuss this in two contexts: ethical issues and the importance of demographics.

\section{Blatantly curbing agency}

In the section "Ethical Implications" (Lin et al., 2017/this issue), the essence of what we are getting at is that opaque nudges are exceptionally hard to defend. As we show, the explanation for why opaque nudges work is deeply flawed, the evidence for opaque nudges working is both weak and rare, the public like them far less than they do transparent nudges, and ethically they are problematic. As Raul (2017/this issue) points out, our approach to tackling ethical concerns around nudge and its impact on our personal control and agency is a practical one. We take some time here to illustrate why taking this approach has some traction, and we hope that it also addresses the seeming shortfall in our discussion on the subject that our commentators allude to.

Given the wealth of academic papers debating the ethics of nudge, has anything changed as a response? The answer depends on the audience being targeted. Sunstein's (2016) recent retort to many academic detractors is that if one takes issue with nudges and their imposition on agency, then one must also take issue with the way the world works. Nudges are, in some form or another, everywhere, and each of us manipulate others on some level fairly regularly. This argument, though poor (Osman, 2016; Schmidt, 2017), is a bold defense from the attacks 


\section{NUDGING: A LESSON IN THE THEATRIC OF CHOICE}

nudges face in the ethical arena, and it provides a handy mantra that choice architects can use to keep them in worriless sleep. By contrast, in a recent paper (Benartzi et al., 2017) designed to convince governments just how cost effective nudges are and why more money should be directed toward implementing them, the ethics debate is not mentioned once. But it is revealing that only one of the seven nudges referred to (none of which were in the health domain) would typically count as an opaque nudge, and even by their own calculations the authors show it to be less effective than virtually all other nudges, as well as typical regulatory methods. Moreover, the poster child of nudges - automatic defaults in the organ procurement domainwas not discussed at all; there are many reasons to suggest that they are simply not effective in increasing actual organ donations (Lin, Osman, Harris, \& Read, 2017). The nudge techniques that the paper advocates are transparent. They are designed to improve the quality of the information on which people make choices, or else improve the opportunities for people to make active choices. One could take issue with the methods used to show their cost efficiency, but it's harder to take issue with the types of behavioral methods they are arguing should be rolled out. After all, they are in line with the kinds of interventions for which the public has shown an appetite, and to which researchers and philosophers have been more sympathetic. In their recent paper (Benartzi et al., 2017), Thaler and Sunstein are clearly taking note of practical factors that in turn point to the same conclusion as the ethical issues. Although one could ask, does it matter that nudge advocates are taking opaque nudges off the table for pragmatic rather than ethical reasons?

\section{Availability of agency's perceptibility}

As Majanovic rightly pointed out, our review doesn't discuss demographic factors; instead it focuses on the psychological processes that nudges are designed to tap into and behavioral outcomes they are purported to achieve. But the critical point that Majanovic (2017/this issue) 


\section{NUDGING: A LESSON IN THE THEATRIC OF CHOICE}

makes in relation to this miscasts our argument. At the end of the first section of the review we present an alternative conceptualization of nudges that differ in degree rather than kind; Type 1 and Type 2 nudges differ based on the extent to which they prompt people to reevaluate their choices. Do we also end that section by suggesting that ultimately most of the variance in bad behavior is down to cognitive factors, such as biased automatic thinking, at the exclusion of noncognitive factors (e.g., education, socioeconomic status [SES], motivation)? Put simply, no, we do not. It is certainly the case that we did not discuss two of these factors (motivation is a factor we did discuss throughout the review), but we have been generously granted the opportunity to now discuss how these factors have a bearing on the topic of volition and nudges.

Let us consider what the essence of Majanovic's (2017/this issue) argument might be, and actually how it relates to volition. Low education and low SES are (Stringhini et al., 2017; Winkleby, Jatulis, Frank, \& Fortmann, 1992), and even perceived classism (Simons, Koster, Groffen, \& Bosma, 2017) are reported closely linked to poor health behaviors, which in turn result in poor health outcomes. Although genetics seem to directly impact health outcomes, the environmental conditions in which people live in impacts health outcomes indirectly through health behaviors. This seems like a legitimate cause for concern because it undermines the view that we can all change our lifestyle choices, which will lead to improvements in our health behaviors and health outcomes. Put another way, volition over lifestyles choices is reserved only for the educated and those with high SES. Is this really the case? Because if it is, then there is simply no room for behavioral change for a disadvantaged majority.

Smoking is a good test case. Those with a low SES are more likely to start smoking early, les s likely to quit successfully, and more likely to be exposed to the harmful consequences of tobacco smoking (Gilman, Abrams, \& Buka, 2003; Hiscock, Bauld, Amos, Fidler, \& Munafò, 2012). Clearly SES is a relevant factor in explaining the prevalence of smoking and in turn 


\section{NUDGING: A LESSON IN THE THEATRIC OF CHOICE}

noncommunicable diseases in poorer and less educated populations. Is there any psychological link between SES and greater resistance to behavioral change in smoking behavior? There appears to be on the basis of perceptions of volition. Perceived control and sense of agency around health behaviors is experienced to a lesser degree in low SES than higher SES (Bailis, Segall, Mahon, Chipperfield, \& Dunn, 2001; Vasiljevic, Ng, Griffin, Sutton, \& Marteau, 2016). Psychology would benefit more from focusing on the interplay between SES and health behaviors (Schüz, 2017) but also how these two factors interact with perceptions of control/agency and motivations for behavioral change (Ashcroft, 2011; Blue, Shove, Carmona, \& Kelly, 2016). In this regard, there are a variety of interventions that can work for different samples (low vs. high SES), but this requires systematic comparisons of interventions that take into account the impact on different SES groups (Brown, Platt, \& Amos, 2014). The point from all this is that it may be harder for some groups to perceive their own agency because the means are harder, motivation is lower, and the sense of agency is fragile, but that only means that better efforts are needed to support agency, conditional on the premise that the motivation for behavioral change exists once relevant information about one's behavior is known.

The nudge strategy is to target a very narrow idea of what the choice environment is, and the context in which it is situated, in order to maximize behavioral change for the greatest number of individuals. It is designed to work on an aggregate level, and so for efficiency sake, a onesize-fits-all choice environment is the one typically constructed. Taking factors such as SES, education, value systems, motivation, economic climate, cultural climate, and political climate, into account is not something that nudge set out to do (Osman, 2016). So, the point regarding factors such as education or SES are incredibly important to bear in mind when considering what types of interventions to use in social policy domains, and where volition needs to be bolstered. 


\section{NUDGING: A LESSON IN THE THEATRIC OF CHOICE}

\section{Nullification of the impact of education}

Given that one of the core conclusions we can draw from our critical discussion of the dualsystem framework, and the evidence in support of nudges, is that if there is any meaningful behavioral change to be achieved practitioners/policymakers need to play the long game. We propose that, of the variety of nudges that are currently being employed, educational campaigns are the most fruitful. Raul (2017/this issue) suggests that their success depends on the general public's savviness on social policy. Does it? Our view on this is that an educational campaign is based on information that explains the need to change behavior (e.g., a new scientific report), it doesn't require an understanding of public policy structures behind the campaign. Nevertheless, extending Raul's point, perhaps an even more general one can be raised, such as, how much can educational campaigns achieve? We would argue, based on our review of the findings, that relative to other nudges, educational campaigns tend to be more effective. But how do they stand up against typical regulatory policy instruments?

For instance, the global rates of smoking cessation have reduced (1990-2015) by approximately $30 \%$ since 1990, and this has been achieved through a combination of strategies implemented over a considerable period that include taxes, bans, and mandates, as well as educational campaigns (Reitsma et al., 2015). The campaigns themselves are devised with audiences in mind and have been shown to be particularly effective (Blue et al., 2016). What more could be done, and does it require more educational campaigns? There are misconceptions that exist across all age groups regarding smoking (e.g., that cigarette filters remove all harmful chemicals from cigarette smoke such as uranium, lead, hydrogen cyanide, arsenic, ammonia; Brewer et al., 2016). The lesson learned in the domain of smoking cessation is an important one. If long-term strategies are put in place, and a combination of behavioral and typical regulatory methods are used, then it is likely that a positive health outcome is going 


\section{NUDGING: A LESSON IN THE THEATRIC OF CHOICE}

to be greater than any individual method alone. The problem for practitioners and policymakers is that they cannot always rely on good empirical support, because it is hard to estimate which combination of methods is most effective, given that in practice multiple methods are used at once.

\section{The purity and probability of utility}

Our presentation of nudges and the theory behind them generally states that Type 1 nudges, which minimally prompt the individual to question their choice behavior differs in degree from a Type 2 nudge that generates substantial reevaluation and questioning of the motives, reasons, and needs for choosing one option over another (Wilding et al., 2016). More to the point, we argue that for theoretical and empirical reasons the focus should be on Type 2 nudges, which is consistent with many ethicists. But this doesn't by default commit us to a utilitarian position as claimed by Raul. From our point of view neither type of nudge, based on the specific nudges we refer to in our review, poses a threat to a utilitarian, republican, Kantian, and Rousseauvian perspective on freedom. Raul conflates two distinct debates in moral philosophy: the debate around how we justify and explain moral norms (so-called normative ethics) and the debate around the connection between moral norms and human psychology in action. Clearly these debates have a lot to say to one another, but one's empirically model of moral cognition does not fix or exhaust what we should say about how we justify particular moral norms. Nor, as Raul proposes, does it render a situation in which a Type 2 nudge is akin to a mandate if it encourages an action where an individual's subjective probability of performing that action differs from the actual probability of that action occurring. It seems highly irregular to imply that a mandate sets up conditions in which people's estimates of likely generating an action fall short of their actual chances of performing it. Nevertheless, the essential point that Raul implies in his discussion does require an equally thoughtful response, and that is, what moral position 
do we take with respect to behavioral interventions? When thinking about the three main philosophical positions (liberalism, utilitarianism, communitarianism) and their application to the health domain. Each of the three main positions asserts its own value system on what, and how, some things should be prioritized over others. We are of the view that thus far none adequately handle the core problems concerning if, or how, the state should intervene, and what position best captures what counts as good (Roberts \& Reich, 2002; Seidman \& Atun, 2016). Also, as empiricists we do not necessarily have to side with any position, but what we should do is accurately reveal how different value systems set the conditions for behavioral change, and what impact, if any, they have on human behavior. 
NUDGING: A LESSON IN THE THEATRIC OF CHOICE

\section{References}

Ashcroft, R. E. (2011). Personal financial incentives in health promotion: Where do they fit in an ethic of autonomy? Health Expectations, 14(2), 191-200. doi:10.1111/j.13697625.2011.00664.x

Bailis, D. S., Segall, A., Mahon, M. J., Chipperfield, J. G., \& Dunn, E. M. (2001). Perceived control in relation to socioeconomic and behavioral resources for health. Social Science \& Medicine, 52(11), 1661-1676. doi:10.1016/s0277-9536(00)00280-x

Benartzi, S., Beshears, J., Milkman, K. L., Sunstein, C. R., Thaler, R. H., Shankar, M., Tucker-Ray, W., Congdon, W. J., ～\& Galing, S. (2017). Should governments invest more in nudging? Psychological Science, 28(8), 1041-1055. doi:10.1177/0956797617702501

Blue, S., Shove, E., Carmona, C., \& Kelly, M. P. (2016). Theories of practice and public health: Understanding (un) healthy practices. Critical Public Health, 26(1), 36-50. doi:10.1080/09581596.2014.980396

Bovens, L. (2009). The ethics of nudge. In T. Grüne-Yanoff \& S. O. Hansson (Eds.), Preference Change: Approaches from Philosophy, Economics and Psychology (pp. 217-209). Dordrecht: Springer Netherlands.

Brewer, N. $\quad$ T., Morgan, J. $\quad$ C., Baig, S. $\quad$ A., Mendel, J. $\quad$ R., Boynton, M. H., Pepper, J. K., ... Ribisl, K. M. (2016). Public understanding of cigarette smoke constituents: Three US surveys. Tobacco Control, 26(5), 592-599. doi:10.1136/tobaccocontrol2015-052897 
Brown, T., Platt, S., \& Amos, A. (2014). Equity impact of population-level interventions and policies to reduce smoking in adults: A systematic review. Drug and Alcohol Dependence, 138, 7-16. doi:10.1016/j.drugalcdep.2014.03.001

De Neys, W., Cromheeke, K., \& Osman, M. (2011). Biased but in doubt: Conflict and decision confidence. PLoS ONE, 6, e15954. doi:10.1371/journal.pone.0015954

Gilman, S. E., Abrams, D. B., \& Buka, S. L. (2003). Socioeconomic status over the life course and stages of cigarette use: Initiation, regular use, and cessation. Journal of Epidemiology \& Community Health, 57(10), 802-808. doi:10.1136/jech.57.10.802

Grüne-Yanoff, T. (2012). Old wine in new casks: Libertarian paternalism still violates liberal principles. Social Choice and Welfare, 38(4), 635-645. doi:10.1007/s00355-011-06360

Hiscock, R., Bauld, L., Amos, A., Fidler, J. A., \& Munafò, M. (2012). Socioeconomic status and smoking: A review. Annals of the New York Academy of Sciences, 1248(1), 107123. doi:10.1111/j.1749-6632.2011.06202.x

Holden, S. S., Zlatevska, N., \& Dubelaar, C. (2016). Whether smaller plates reduce consumption depends on who's serving and who's looking: A meta-analysis. Journal of the Association for Consumer Research, 1(1), 134-146. doi:10.1086/684441

Lin, Y., Osman, M., Harris, A., \& Read (2017). Underlying wishes and nudged choices. Under Review.

Lin, Y., Osman, M., \& Ashcroft, R. (2017/this issue). Nudging: A lesson in the theatrics of choice. Basic and Applied Social Psychology. doi:10.1080/01973533.2017.1375929 
NUDGING: A LESSON IN THE THEATRIC OF CHOICE

Marjanovic, Z. (2017/this issue). The fruitless pursuit of nudging healthy behavior: Comment on Lin, Osman, and Ashcroft. Basic and Applied Social Psychology.

McLeish, H. (2017). Citizens united: Taking back control in turbulent times. Edinburgh, UK: Luath Press Ltd.

Osman, M. (2004). An evaluation of dual process theories of reasoning. Psychonomic Bulletin \& Review, 11, 998-1010. doi:10.3758/bf03196730

Osman, M. (2007). Can tutoring improve performance on a reasoning task under deadline conditions? Memory \& Cognition, 35, 342-351. doi:10.3758/bf03193455

Osman, M. (2010). Controlling uncertainty: A review of human behavior in complex dynamic environments. Psychological Bulletin, 136, 65-86. doi:10.1037/a0017815

Osman, M. (2013). A case study dual-process theories of higher cognition - Commentary on Evans \& Stanovich (2013). Perspectives on Psychological Science, 8(3), 248-252. doi:10.1177/1745691613483475

Osman, M. (2014). Future-minded: The psychology of agency and control. New York: Palgrave-MacMillan.

Osman, M. (2016). Nudge: How far have we come? Economia. History, Methodology, Philosophy, (6-4), 557-570.

Osman, M., \& Stavy, R. (2006). Intuitive rules: From formative to developed reasoning. Psychonomic Bulletin \& Review, 13, 935-953.

Rauh, J. (2017/this issue). On the limits of type 1 and type 2 nudges as instruments of public policy: Commentary on nudging. Basic and Applied Social Psychology. 
Reitsma, M., Fullman, N., Ng, M., Salama, J.

S., Abajobir, A., ... Gakidou, E. (2015). Smoking prevalence and attributable disease burden in 195 countries and territories, 1990-2015: A systematic analysis from the Global Burden of Disease Study 2015. The Lancet, 389, 1885-1906. doi:10.1016/s0140-6736(17)30819-x

Roberts, M. J., \& Reich, M. R. (2002). Ethical analysis in public health. The Lancet, 359(9311), 1055-1059. doi:10.1016/s0140-6736(02)08097-2

Robinson, E., Kersbergen, I., Brunstrom, J. M., \& Field, M. (2014). I'm watching you. Awareness that food consumption is being monitored is a demand characteristic in eating-behaviour experiments. Appetite, 83, 19-25. doi:10.1016/j.appet.2014.07.029

Robinson, E., Proctor, M., Oldham, M., \& Masic, U. (2016). The effect of heightened awareness of observation on consumption of a multi-item laboratory test meal in females. Physiology \& Behavior, 163, 129-135. doi:10.1016/j.physbeh.2016.04.044

Schmidt, A. T. (2017). The power to nudge. American Political Science Review, 111(2), 404417. doi:10.1017/s0003055417000028

Schüz, B. (2017). Socio-economic status and theories of health behaviour: Time to upgrade a control variable. British Journal of Health Psychology, 22(1), 1-7. doi:10.1111/bjhp.12205

Seidman, G., \& Atun, R. (2016). Aligning values and outcomes in priority-setting for health. Journal of Global Health, 6(2), 020308. doi:10.7189/jogh.06.020308

Simons, A. M., Koster, A., Groffen, D. A., \& Bosma, H. (2017). Perceived classism and its relation with socioeconomic status, health, health behaviours and perceived inferiority: 
NUDGING: A LESSON IN THE THEATRIC OF CHOICE

The Dutch Longitudinal Internet Studies for the Social sciences (LISS) panel. International Journal of Public Health, 62, 422-440. doi:10.1007/s00038-016$0880-2$

Stringhini, S., Carmeli, C., Jokela, M., Avendaño, M., Muennig, P., Guida, F., ... ChadeauHyam, M. (2017). Socioeconomic status and the $25 \times 25$ risk factors as determinants of premature mortality: A multicohort study and meta-analysis of 1-7 million men and women. The Lancet, 389, 1229-1237. doi:10.1016/s0140-6736(16)32380-7

Sunstein, C. (2016). The Ethics of Influence: Government in the Age of Behavioral Science. Cambridge: Cambridge University Press.

Vasiljevic, M., Ng, Y. L., Griffin, S. J., Sutton, S., \& Marteau, T. M. (2016). Is the intentionbehaviour gap greater amongst the more deprived? A meta-analysis of five studies on physical activity, diet, and medication adherence in smoking cessation. British Journal of Health Psychology, 21, 11-30. doi:10.1111/bjhp.12152

Wansink, B. (2007). Mindless eating: Why we eat more than we think. New York: BantamDell.

Wilding, S., Conner, M., Sandberg, T., Prestwich, A., Lawton, R., Wood, C., ... Sheeran, P. ( 2016). The question-behaviour effect: A theoretical and methodological review and meta-analysis. European Review of Social Psychology, 27, 196-230. doi:10.1080/10463283.2016.1245940

Winkleby, M. A., Jatulis, D. E., Frank, E., \& Fortmann, S. P. (1992). Socioeconomic status and health: How education, income, and occupation contribute to risk factors for 
NUDGING: A LESSON IN THE THEATRIC OF CHOICE

cardiovascular disease. American Journal of Public Health, 82, 816-820. doi:10.2105/ajph.82.6.816 